\title{
Comparison and Mathematical Modelling of Leakage Tests
}

\author{
Kamil Fojtášek ${ }^{1, \mathrm{a}}$, Lukáš Dvořák ${ }^{2}$, Lukáš Krabica $^{3}$ \\ 1, 2, 3 VŠB-Technical University of Ostrava, Faculty of Mechanical Engineering, Department of Hydrodynamics \\ and Hydraulic Equipment, 17. listopadu 15/2172, Ostrava 70833, Czech Republic
}

\begin{abstract}
Leak tests are used in many industrial applications, a typical example are the headlights of cars. In these tests are use different principles and different working media. The monitored parameters are usually the amount of leakage media depending on the pressure drop and the time at which the leakage occurs. The article describes the possibility of performing leak tests using compressed air, their comparison and the subsequent creation of mathematical models.
\end{abstract}

\section{Introduction}

Leak tests are used in many different areas of industry. Very important is the use in medical devices where high purity and environmental sterility is required. If leakage occurs, the fluids may be sent to the incorrect place or the wrong liquid may be removed. Any leakage can result in dangerous consequences and expose medical workers or patients to a hazardous situation. Leak testing is used, for example, in medical bags, catheters, medical valves, filter membranes, tubing and fittings, or condoms etc. Another major area of use is the packaging industry. Examples of such packaging types are bottle caps, trigger pumps, aerosol cans and valves, ink cartridges, cosmetic bottles, food sachets and other various types of packaging. In the mechanical industry, leakage of liquids or gases may negatively affect the properties of metal or plastic materials. Another factor is the possible environmental contamination. A next large area of application is automotive. Typical applications for automotive leak testing are brake calipers, muffler, catalytic converter, radiators, fuel lines, truck brakes. In the engine they are intake manifold, head or turbo. And the headlights are also included in this group [1].

Leakage can be defined as a crack, hole or porosity in the surrounding wall of element or device where is the enclosed medium. The most likely areas of leakage in closed systems are usually joints, sealing elements, bearing surfaces, welded and soldered joints, and many others. Three basic criteria are usually used for leak testing: a) Detection - determining if there is a leakage or not. b) Measurement of leak rate. c) Leakage location. The use of one or more of the above criteria depends on the type of test and subsequent application. For some applications, leakage detection information is sufficient. In other cases, it is necessary to determine the exact size of leakage and compare it with the so-called reference value.

\footnotetext{
${ }^{\mathrm{a}}$ Corresponding author: kamil.fojtasek@vsb.cz
}

There are many methods to test the tightness of an element or device, which are based on very simple principles, such as bubble test or pressure decay test in closed volume. For complex systems is using the marking gas. For compressible gases, their volume depends on the pressure and is expressed in milibars. Where $1 \mathrm{mbar} \mathrm{dm}^{3} \cdot \mathrm{s}^{-1}$ is at atmospheric conditions equal to a leakage rate of $1 \mathrm{dm}^{3}$ of gas per second. The most commonly used leak testing methods in the industrial environment are: bubble test (underwater test), bubble method (soap painting), pressure and vacuum decay method and methods using detection/marking gas (halogen, helium and hydrogen). These methods are differ in sensitivity range [2].

\section{Theory of measurement}

Each of leak testing method has advantages and disadvantages. For the choice of a suitable testing method is important the required sensitivity of the test method, repeatability of the test, accuracy, reliability, processing difficulty and test cost. In the case of large scale leakage checks, where is usually using method with the marking gas, it is important the price of used gas. In most cases, it is necessary to ensure the correct way of recovering the used marking gas. Leakage measurement in the Czech Republic is defined by the standard ČSN 109006. The tightness is checked by measuring the pressure in the closed volume for a specified time (in each space of the test element) at the nominal pressure. If the sealing of the seals used requires a certain pressure drop, the test is carried out even at minimum pressure. The pressure drop $[\mathrm{MPa}]$ in the closed volume, at time $\mathrm{t}$, may not be greater than the value calculated from the formula:

$$
\Delta p=\frac{q_{d} \cdot t \cdot p_{a}}{V}
$$

where $\mathrm{q}_{\mathrm{d}}\left[\mathrm{cm}^{3} \cdot \mathrm{min}^{-1}\right]$ is the largest air leak, corresponding to the leakage values, $\mathrm{t}$ [min] duration of the 
test, $\mathrm{p}_{\mathrm{a}}[\mathrm{MPa}]$ pressure of the environment in which the losses incurred, $\mathrm{V}\left[\mathrm{cm}^{3}\right]$ closed volume (summation volume of the element chamber, measuring device, tube etc.).

However, other methods of determining air leakage are also permissible, if providing comparable results. As mentioned above, we will deal with the comparison and subsequent modeling of leak tests for the application of headlight of a car. For this type of task, three different leak measurement methods were selected.

Method of pressure decay in closed volume (pressure drop): This method is based on the principle of pressurized the system with high pressure gas (compressed air). Then the testing element is isolated from pressure supply and after the stabilization period is monitored internal pressure over time. The pressure loss $\Delta \mathrm{p}$ is measured in time $\Delta \mathrm{t}$. If the system pressure drops rapidly, there is a greater leak in the element, if drops slowly, it is a leak of smaller dimensions. If the pressure in the testing element does not change over a certain period of time, it is considered tight. The leakage rate $\mathrm{Q}$ can be easily calculated with respect to the volume $\mathrm{V}$ of the element.

$$
Q=\frac{\Delta p \cdot V}{\Delta t}
$$

Sensitivity of leakage detection depends on test time, on used type of pressure sensor and on volume of testing element. Several external factors, such as temperature changes or mechanical deformations, may affect the result of this test. Internal pressure depends on temperature and temperature fluctuations in the surrounding environment, these fluctuations can cause pressure changes that may affect the course of the test. Long test times allow for more sensitive measurements, but they can be time consuming, (for example in the case of leaks of small dimensions). If the test gas pressure is increased, then the leakage is detected more quickly. However, it must be take care of the operator's safety. The safety guidelines limit the maximum allowable pressure without safety equipment to $2 \mathrm{MPa}$ for low pressure elements and $7 \mathrm{MPa}$ for high pressure (with using a safety equipment according to EN378). Usually, the sensitivity limit of this method is in the range of $10^{-3} \mathrm{mbar} \cdot \mathrm{dm}^{3} \cdot \mathrm{s}^{-1}$ to $10^{-4} \mathrm{mbar} \cdot \mathrm{dm}^{3} \cdot \mathrm{s}^{-1}$. The disadvantage of this method is that does not identify the leak location (only size of leak).

Method of vacuum decay in closed volume (the pressure rise): The pressure rise method is based on the opposite principle as the pressure drop method. The test element is depressurized and after the stabilization period, the pressure increase over time $\Delta t$ is measured, due to the penetration of the medium into the test element space. In this way, only elements capable of withstanding external pressure can be tested. (eg thin-walled plastic parts cannot be tested due to the risk of element collapse). The advantage of this method is less sensitivity to temperature changes (lower pressure than atmospheric). Vacuum sensors are usually very sensitive to small changes in pressure, therefore the theoretical sensitivity of this method is high up to $10^{-5} \mathrm{mbar} \cdot \mathrm{dm}^{3} \cdot \mathrm{s}^{-1}$. However, the measurement may be impaired by increasing the pressure due to evaporation of the liquid within the test element.
Flow test leakage method: The flow test leakage is based on the principle of using a constant flow rate and subsequent measurement of the leakage media through the flowmeter. When used in pneumatic devices at atmospheric pressure, the test element is placed on the side of the air pressure source and the flowmeter on side of atmospheric pressure. The test pressure is supplied to the test element via the airflow regulator, which determines the flow through the system. The leaked air is then shown by the flowmeter as the difference between the regulated flow in front of the measured element and the flow displayed by the flow meter behind the test element. The size of the difference between this flow determines the size of the leakage. If the flow rate is equal to flow through the element, this element can be considered tight.

\section{Measurement methodology}

Experimental verification of leakage was carried out using a reservoir with volume $2 \mathrm{dm}^{3}$, which approximately corresponds to the size of the automobile headlight. The volume of the reservoir was added to the volume of the connected tubes, the total closed volume being $2.046 \mathrm{dm}^{3}$.

For method of pressure decay in closed volume the measurement scheme is shown in Fig.1.

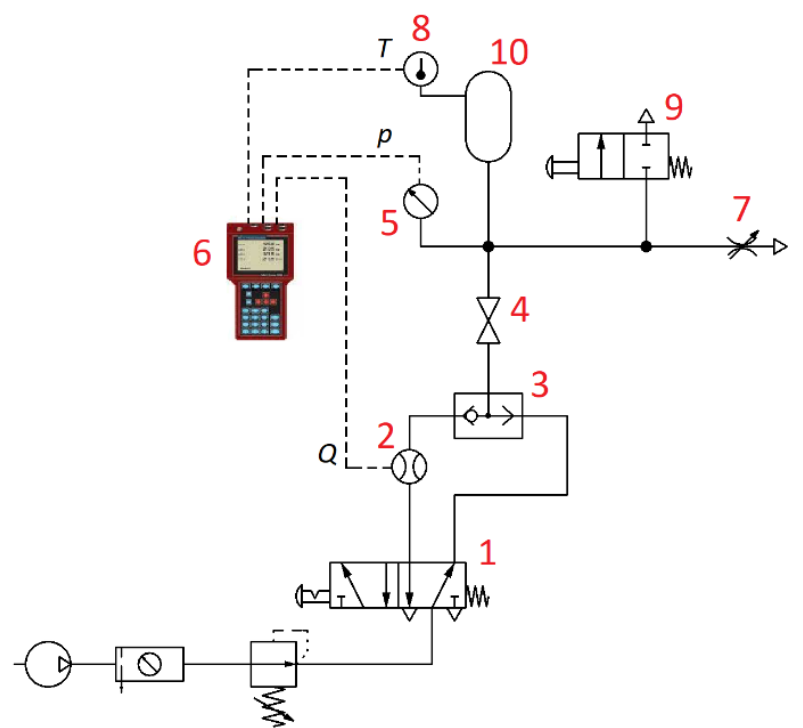

Fig. 1. Scheme of the measurement for method of pressure decay in closed volume

1 -directional control valve, 2 -flow meter, 3 -shuttle valve, 4 -shutoff valve, 5 - pressure sensor, 6 - measuring equipment M5050, 7 -throttle valve, 8 - thermometer, 9 -direction control valve (exhaust), 10 - reservoir (measured element)

The leakage was simulated via a throttle valve 7 , which was set to a constant flow rate $1 \mathrm{dm}_{\mathrm{N}}^{3} \cdot \mathrm{min}^{-1}$. A temperature sensor 8 is connected to the reservoir, which measures the temperature during each measurement. The pressure sensor 5 (which measuring pressure drop), the flowmeter 2 and temperature sensor were connected to the M5050 measuring equipment 6 . Five measurements were recorded for each set pressure value. Each measurement was carried out for $70 \mathrm{~s}$, with a sampling frequency of $50 \mathrm{~ms}$. 


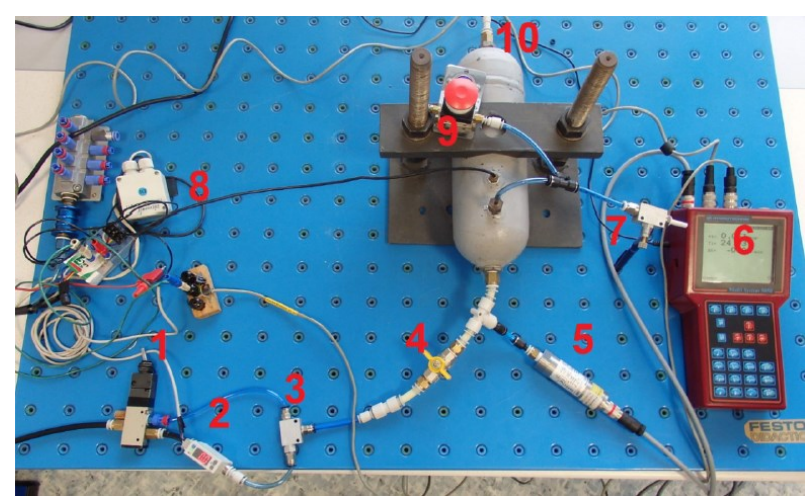

Fig. 2. Realization of measurement for method of pressure decay in closed volume

1 -directional control valve, 2 -flow meter, 3 -shuttle valve, 4 -shutoff valve, 5 - pressure sensor, 6 - measuring equipment M5050, 7 -throttle valve, 8 - thermometer, 9 -direction control valve (exhaust), 10 - reservoir (measured element)

The measurements were carried out according to the following procedure. After pressurizing system by the compressor, the constant pressure was set up by reducing valve for each measurement (successively 0.5, 0.4, 0.2, 0.1 $\mathrm{MPa}$ ). Compressed air flows through the $5 / 2$ mechanical control directional valve 1 , logic valve 3 and via shutoff valve 4 into the reservoir 10 . The reservoir 10 was filled for ten seconds, after this time the shutoff valve 4 was closed to stabilize the pressure in the reservoir. After closing the valve 4 , the pressure drop in reservoir was recorded by the pressure sensor 5 for $60 \mathrm{~s}$. The realization of the measurements is shown in Fig. 2.

The graph Fig. 3 shows the average pressure drop of measuring leakage by the method of pressure decay in closed volume, for all set up inlet constant pressure values. For each set pressure, there were 5 measurements from which the average values and curves were plotted as a dependence of pressure in measured element on time.

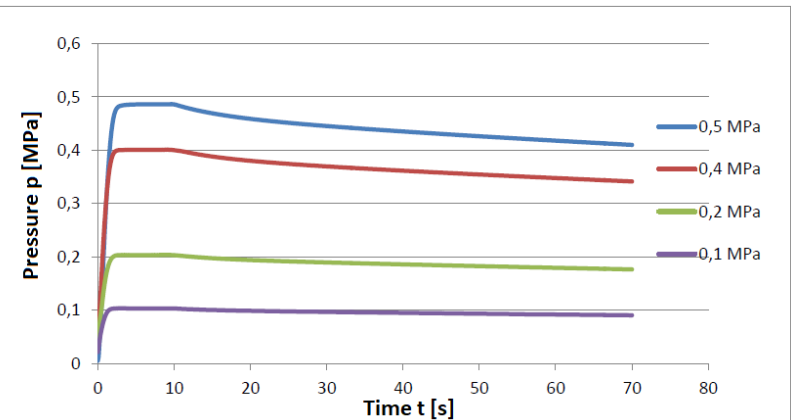

Fig. 3. Diagram of average values of pressure drop in the reservoir as a function of time

The average drop in pressures for all measurements ranged around $14.1 \%$ (from the beginning to the end of the measurement). Table 1 shows the results of the average pressure values at the start and end of the measurement together with the pressure drop from the start of the measurement in [\%] for all the set pressure values. It is obvious that the pressure drop depends on the size of pressure in the measured element (the higher pressure means the greater pressure drop during the measurement).
Tab. 1. Average pressure drop in reservoir

\begin{tabular}{|c|c|c|}
\hline $\begin{array}{c}\text { Average pressure } \\
\text { at measurement } \\
\text { start } \\
{[\mathrm{MPa}]}\end{array}$ & $\begin{array}{c}\text { Average pressure } \\
\text { at the end of the } \\
\text { measurement } \\
{[\mathrm{MPa}]}\end{array}$ & $\begin{array}{c}\text { Pressure drop } \\
{[\%]}\end{array}$ \\
\hline 0.4865 & 0.41006 & 15.63 \\
\hline 0.401 & 0.34952 & 14.71 \\
\hline 0.2037 & 0.1767 & 13.28 \\
\hline 0.1035 & 0.09072 & 12.39 \\
\hline
\end{tabular}

Measuring circuit for method of vacuum decay in closed volume consisted of the same elements as in the previous method. Measurement scheme is shown in Fig.4. A vacuum ejector 11 was connected to the circuit through which the air pressure was depressed to the vacuum values. This values were measured in reservoir. Leakage was again simulated by the throttle valve with the same settings. The increase in pressure (decrease of vacuum) over time was measured by a pressure sensor 5 . The pressure was reduced in the reservoir until a constant vacuum value $(0.06,0.04,0.02 \mathrm{MPa})$ was reached. Than the shutoff valve 4 was closed to stabilize the vacuum and the measurement was started. One measurement took 70 seconds (for each pressure value the measurement was repeated five times). During the measurement time, pressure was increased in the reservoir due to simulated leakage. At the end of each measurement, the reservoir was pressurized to atmospheric pressure by the directional control valve 9 . Then the next measurement began. The realization of the measurement is shown in Fig.5.

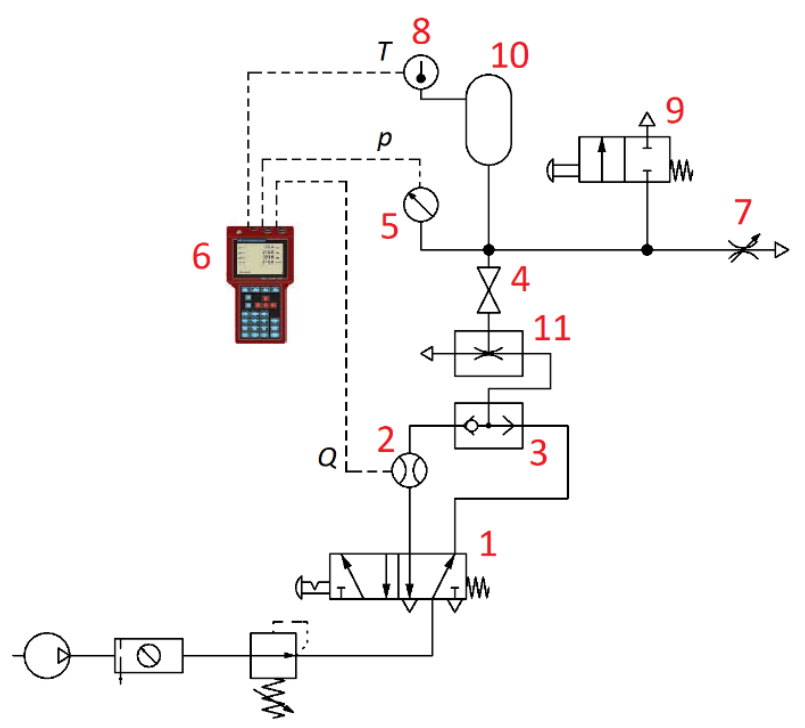

Fig. 4. Scheme of the measurement for method of vacuum decay in closed volume

1 -directional control valve, 2 -flow meter, 3 -shuttle valve, 4 -shutoff valve, 5 - pressure sensor, 6 - measuring equipment M5050, 7 - throttle valve, 8 - thermometer, 9 -direction control valve, 10 - reservoir (measured element), 11 -vacuum ejector 


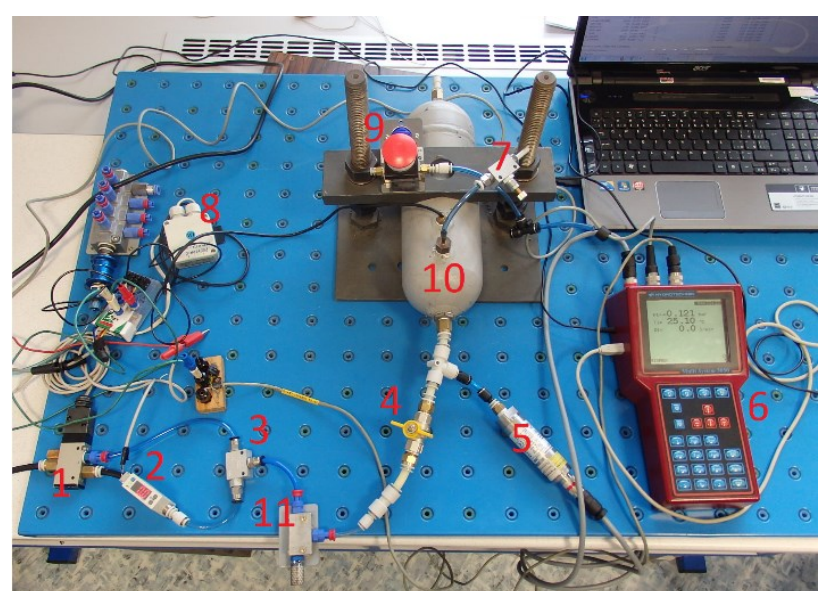

Fig. 5. Realization of the measurement for method of vacuum decay in closed volume

1 -directional control valve, 2 -flow meter, 3 -shuttle valve, 4 -shutoff valve, 5 - pressure sensor, 6 -measuring equipment M5050, 7 -throttle valve, 8 - thermometer, 9 -direction control valve, 10 - reservoir (measured element), 11 -vacuum ejector

The graph Fig.6 shows the average pressure increase by the method of vacuum decay in closed volume, for all set up inlet constant vacuum values. For each set vacuum, there were 5 measurements from which the average values and curves were plotted as a dependence of pressure in measured element on time (the vacuum is shown in positive values). The average increase in pressures for all measurements ranged around $5.8 \%$ (from the beginning to the end of the measurement). Table 2 shows the results of the average pressure values at the start and end of the measurement together with the pressure increase from the start of the measurement in [\%] for all the set vacuum values.

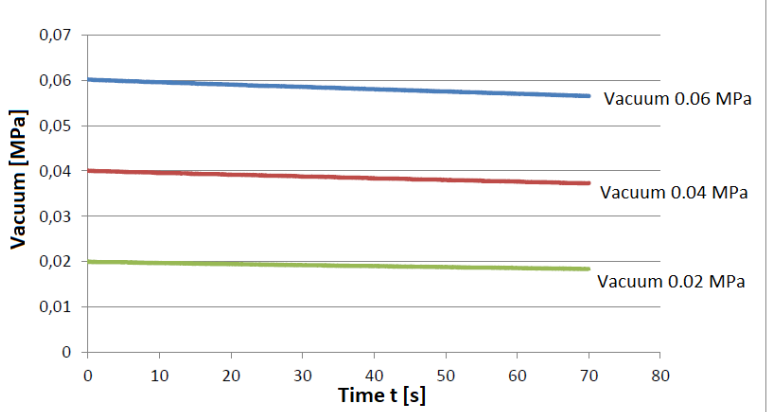

Fig. 6. Diagram of average values of pressure increase in the reservoir as a function of time

Tab. 2. Average pressure increase in reservoir

\begin{tabular}{|c|c|c|}
\hline $\begin{array}{c}\text { Average vacuum } \\
\text { at measurement } \\
\text { start } \\
{[\mathrm{MPa}]}\end{array}$ & $\begin{array}{c}\text { Average vacuum } \\
\text { at the end of the } \\
\text { measurement } \\
{[\mathrm{MPa}]}\end{array}$ & $\begin{array}{c}\text { Pressure increase } \\
{[\%]}\end{array}$ \\
\hline 0.0601 & 0.0565 & 5.1 \\
\hline 0.03962 & 0.03734 & 5.75 \\
\hline 0.0197 & 0.01838 & 6.7 \\
\hline
\end{tabular}

For flow test leakage method is scheme of measuring track same like Fig.1. But in this method we have source of constant pressure regulated by reduction valve. After pressurizing system to the constant pressure (successively $0.5,0.4,0.2,0.1 \mathrm{MPa}$ ) was switched a directional control valve 1 (after five seconds), and then the compressed air flowing through the flow meter. The time of measurement was $70 \mathrm{~s}$ and was repeated five times for each constant value of pressure. The graph Fig.7 shows the average value of flow rate in this method, for all set up inlet constant pressure values.

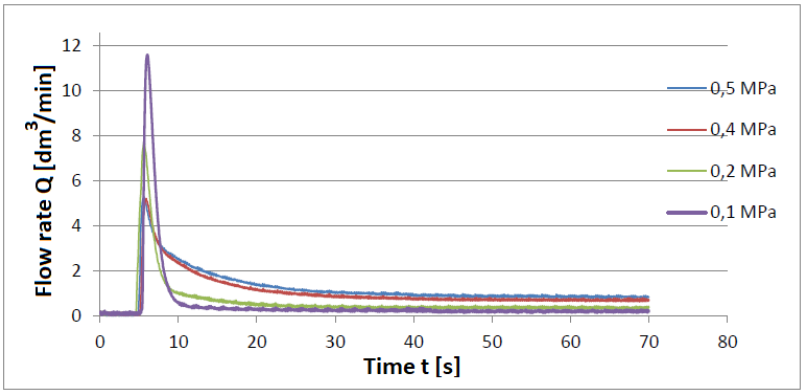

Fig. 7. Diagram of average values of flow rate due to leakage as a function of time

The jump change in the fifth second was caused by switching the 5/2 directional control valve. For all set constant pressures, the steady flow rate was different. The higher the constant pressure was set, the longer the time required to stabilize the flow. Time to stabilize flow and the value of flow rate for each constant values of pressure are in Tab.3. [3]

Tab. 3. The time to stabilize of flow rate

\begin{tabular}{|c|c|c|}
\hline $\begin{array}{c}\text { Constant pressure } \\
\text { in system } \\
{[\mathrm{MPa}]}\end{array}$ & $\begin{array}{c}\text { Time to stabilize } \\
\text { the flow rate } \\
{[\mathrm{s}]}\end{array}$ & $\begin{array}{c}\text { Value of steady } \\
\text { flow rate } \\
{\left[\mathrm{dm}^{3} \cdot \mathrm{min}^{-1}\right.}\end{array}$ \\
\hline 0.1 & 15 & 0.252 \\
\hline 0.2 & 25 & 0.317 \\
\hline 0.4 & 35 & 0.681 \\
\hline 0.5 & 40 & 0.843 \\
\hline
\end{tabular}

The results from measurement was compared with mathematical models.

\section{Mathematical model}

The models were created using the Matlab Simulink software and by the Simscape library blocks. The Ode $15 \mathrm{~s}$ (Stiff / NDF) solver was used for the calculation. Fig. 10. shows the model for the method of pressure decay in closed volume. For other methods the models were very similar only with minor modifications. The reservoir (measured element) is defined by block Constant volume pneumatic chamber, where was setup the volume of reservoir $2.046 \mathrm{dm}^{3}$. This block has two ports, port A is the pneumatic conserving port associated with the chamber inlet. And port $\mathrm{H}$ is a thermal conserving port associated with the thermal mass of gas in the chamber. By this port was defined the heat exchange with the chamber wall and further with the environment. In model this heat exchange is represent by blocks Ideal temperature source and Convective heat Fig.8, their settings was described in previous article $[4,5]$. 


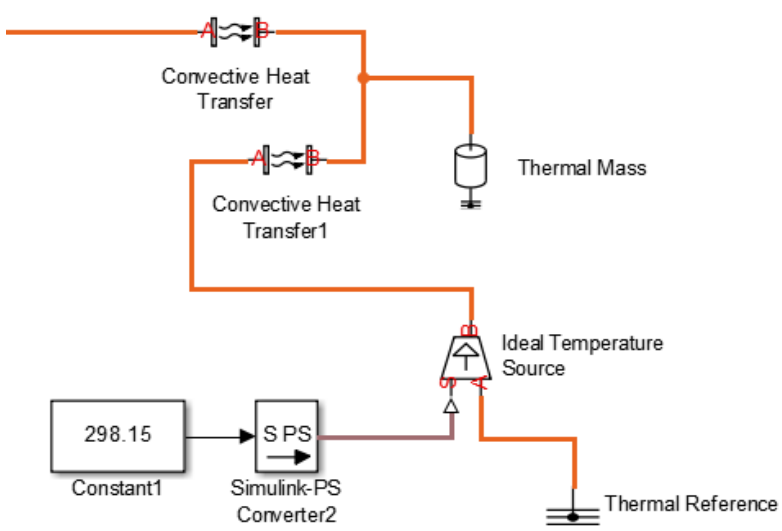

Fig. 8. Blocks in mathematical model for setup the heat exchange

The leakage is represent by the block Constant area pneumatic orifice, where the discharge coefficient is $\mathrm{C}_{\mathrm{d}}=0.68$ and orifice area is $1.7 \mathrm{e}^{-8} \mathrm{~m}^{2}$. The settings of this block was same for every three simulated methods, like in measurement. Since the Matlab Simulink Simscape library does not contain a shutoff valve, it is necessary to use a throttling valve with an area so small as not to affect the simulation results. In model the shutoff valve represent block Variable area pneumatic orifice. Closing or opening of this valve was controlled by block Signal builder.

\section{Conclusion}

When comparing results of measurements and simulations the best match was reached for method of pressure decay in closed volume Fig.9. The average drop in pressure for all constant pressures ranged around 12\%. The course of pressure drop and value of pressure over the test time varied in range $1 \div 2 \%$.

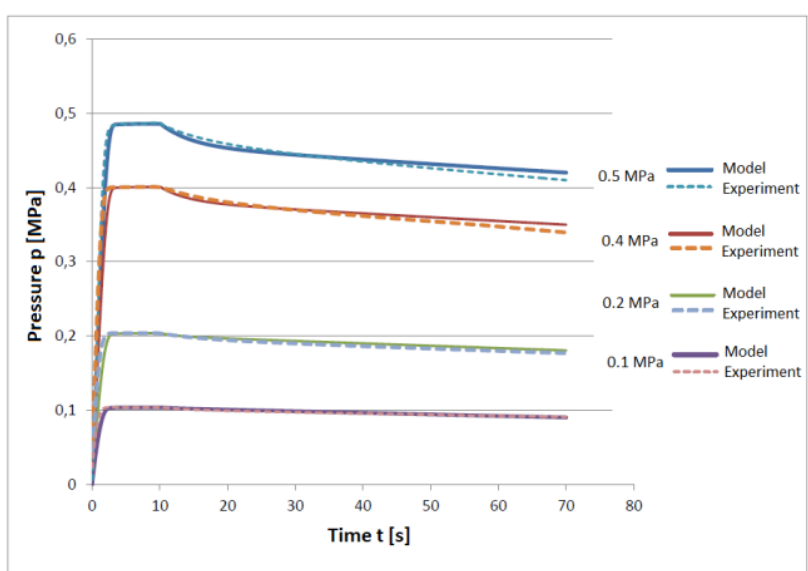

Fig. 9. Comparison of experimental data with simulation for method of pressure decay in closed volume

Comparisons of for each inlet constant pressure are in Tab.4.

Tab. 4. Comparison of experimental measured data with data from mathematical model for method of pressure decay in closed volume

\begin{tabular}{|c|c|c|c|}
\hline $\begin{array}{c}\text { Inlet/setup } \\
\text { pressure } \\
{[\mathrm{MPa}]}\end{array}$ & $\begin{array}{c}\text { Pressure } \\
\text { drop } \\
\text { experiment } \\
{[\%]}\end{array}$ & $\begin{array}{c}\text { Pressure } \\
\text { drop model } \\
{[\%]}\end{array}$ & $\begin{array}{c}\text { Difference } \\
\text { between } \\
\text { experiment } \\
\text { and model } \\
{[\%]}\end{array}$ \\
\hline 0.486 & 15.63 & 13.61 & 2.02 \\
\hline 0.401 & 14.71 & 12.72 & 1.98 \\
\hline 0.203 & 13.28 & 11.41 & 1.86 \\
\hline 0.103 & 12.39 & 11.27 & 1.11 \\
\hline
\end{tabular}

For method of vacuum decay in closed volume was difference between measuring and simulation about $4 \div 7 \%$. With increasing size of the vacuum, this difference is increased. The leakage (pneumatic orifice) showed a greater permeability in the simulation. Comparison for this method is in Fig.11.

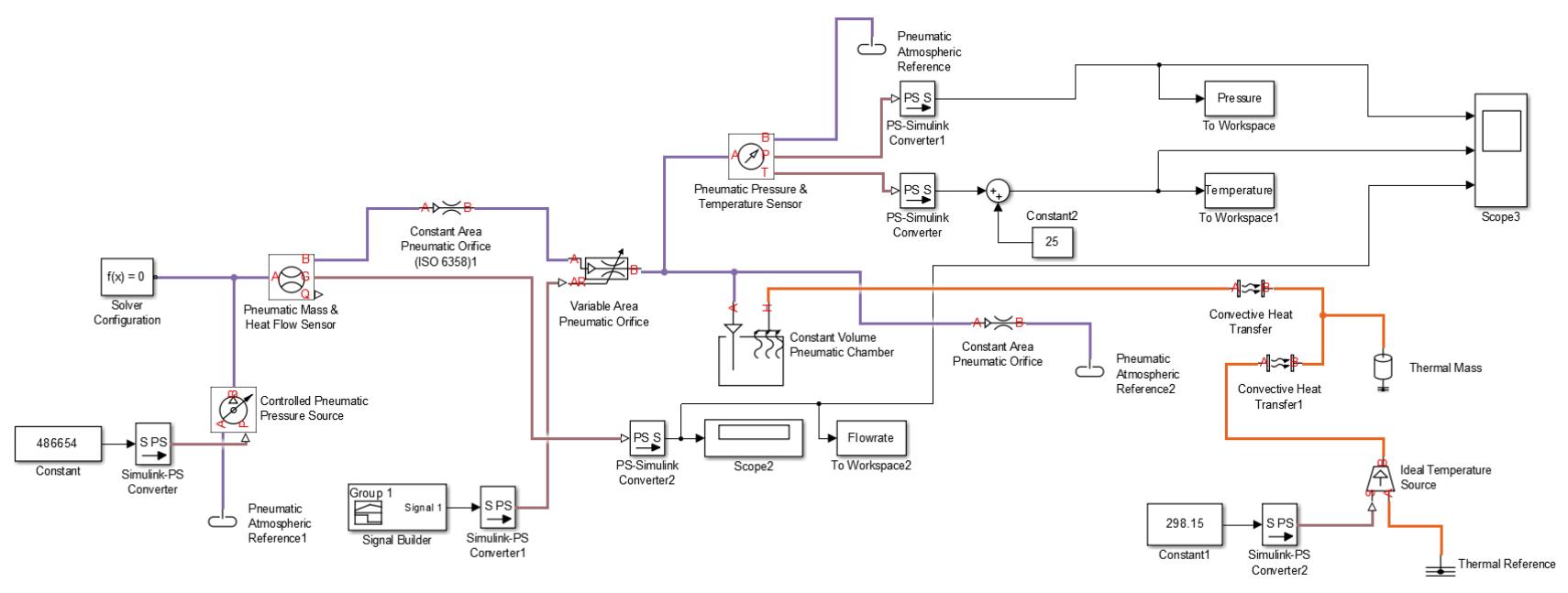

Fig. 10. Mathematical model for method of pressure decay in closed volume 


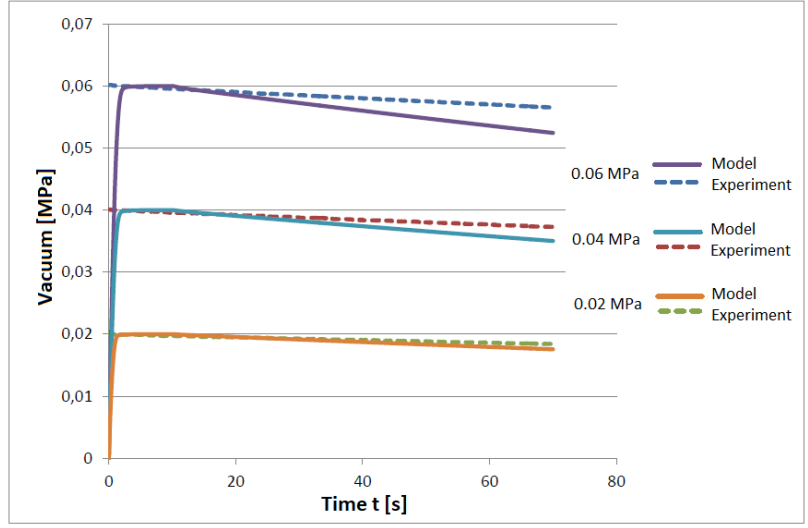

Fig. 11. Comparison of experimental data with simulation for method of vacuum decay in closed volume

Comparisons for each inlet constant vacuum are in Tab.5.

Tab. 5. Comparison of experimental measured data with data from mathematical model for method of vacuum decay in closed volume

\begin{tabular}{|c|c|c|c|}
\hline $\begin{array}{c}\text { Inlet/setup } \\
\text { vacuum } \\
{[\mathrm{MPa}]}\end{array}$ & $\begin{array}{c}\text { Vacuum } \\
\text { drop } \\
\text { experiment } \\
{[\%]}\end{array}$ & $\begin{array}{c}\text { Vacuum } \\
\text { drop model } \\
{[\%]}\end{array}$ & $\begin{array}{c}\text { Difference } \\
\text { between } \\
\text { experiment } \\
\text { and model } \\
{[\%]}\end{array}$ \\
\hline 0.06 & 5.1 & 12.76 & 7.66 \\
\hline 0.04 & 5.75 & 11.61 & 5.86 \\
\hline 0.02 & 6.7 & 10.85 & 4.15 \\
\hline
\end{tabular}

The worst match was for flow test leakage method. Comparison between measured values and simulation is in Fig. 12. Comparison start at 5 seconds, because when the directional control valve was switched the flow rate extremely increase (both in measurement and simulation). The difference was from $0.2 \%$ to $10 \%$ but in both positive and negative values. In view of the fact that they are relatively small values of flow rates, the experiment will be repeated in the future with a higher resolution flow sensor.

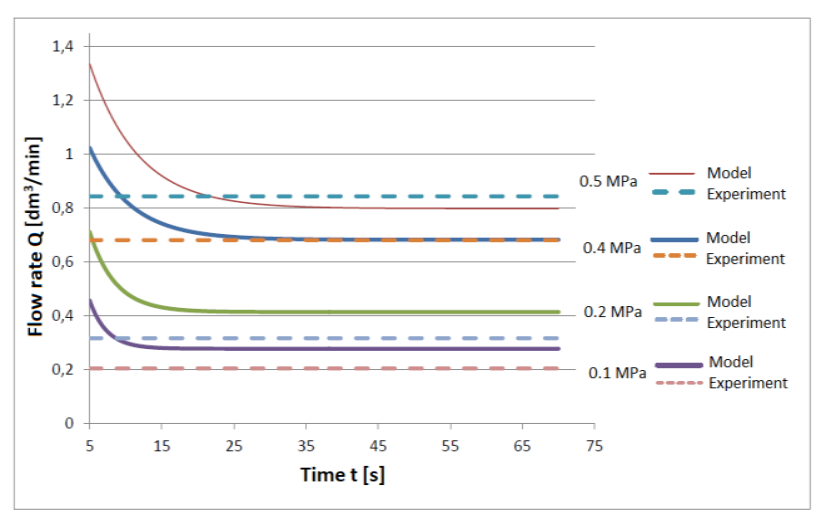

Fig. 12. Comparison of experimental data with simulation for flow test leakage method

Comparisons of for each inlet constant pressure are in Tab.6.
Tab. 6. Comparison of experimental measured data with data from mathematical model for flow test leakage method

\begin{tabular}{|c|c|c|c|}
\hline $\begin{array}{c}\text { Inlet/setup } \\
\text { pressure } \\
{[\mathrm{MPa}]}\end{array}$ & $\begin{array}{c}\text { Steady flow } \\
\text { rate } \\
\text { experiment } \\
{\left[\mathrm{dm}^{3} \cdot \mathrm{min}^{-1}\right]}\end{array}$ & $\begin{array}{c}\text { Steady flow } \\
\text { rate model } \\
{\left[\mathrm{dm}^{3} \cdot \mathrm{min}^{-1}\right]}\end{array}$ & $\begin{array}{c}\text { Difference } \\
\text { between } \\
\text { experiment } \\
\text { and model } \\
{[\%]}\end{array}$ \\
\hline 0.486 & 0.8435 & 0.798 & 5.37 \\
\hline 0.401 & 0.681 & 0.682 & 0.17 \\
\hline 0.203 & 0.371 & 0.414 & 10.41 \\
\hline 0.103 & 0.252 & 0.278 & 9.37 \\
\hline
\end{tabular}

The measuring device and pneumatic system has been assembled with a view to rapid change of measuring method. Measurement time is the shortest for flow rate test method (but increases with increasing pressure). If the important information is only to know if there is a leakage or not, then can be used all three methods. I would recommend using the method of pressure decay in closed volume, of course with respect on testing pressure and material of the measured element.

When defining a mathematical model of leakage the biggest problem is to determine the size of leakage correctly. This type of mathematical model can be used for the calculation of flow losses in pneumatic mechanism. These losses can simply be expressed in money, which is very important because compressed air is one of the most expensive energy sources.

This work was supported by the grant SGS „Modeling and Experimental Verification of Dynamic Phenomena in Fluid and Vacuum Systems" SP2018/157.

This work was supported by the European Regional Development Fund in the Research Centre of Advanced Mechatronic Systems project, project number CZ.02.1.01/0.0/0.0/16 019/0000867 within the Operational Programme Research, Development and Education.

\section{References}

1. ATEQ Leak/Flow Testing, online https://atequsa.com/leak-testing-applications/

2. VTech, Leak Detection Methods: A Comparative Study of Technologies and Techniques, online http://cdn.thomasnet.com/ccp/20106502/32497.pdf

3. L. Krabica, Comparing Tightness Test of Headlights, Magister Thesis, (2018)

4. L. Dvořák, J. Kopčák, Možnosti modelování pneumatických systémů pomoci Matlab-Simulink Simscape, Hydraulika a pneumatika, XV(1-2), (2013)

5. L. Dvořák, K. Fojtášek, V. Řeháček, Calculations of Parameters and Mathematical Model of Rotary air Motor, EPJ Web of Conferences, Volume 143 (2017) 